\title{
Impact of Chorus Club Experience on Students' Vocal Health
}

\author{
Xiang Hongxing ${ }^{1,}{ }^{*}$, Yuan Zhen ${ }^{2}$ \\ Shanghai Normal University Tianhua College, Shanghai, China \\ *hongxing33@126.com
}

\begin{abstract}
To explore the effect of chorus club experience on students' vocal health, this study employs a quantitative method to compare the difference of self-reported vocal health status before and after joining the chorus for 15 months. Choral members $(\mathrm{N}=49)$ were surveyed prior to beginning of joining the choir in September 2015, and then surveyed after a 15-month choral training in December 2016. Vocal problems were reported significantly reduced and vocal health and capacity were significantly improved.
\end{abstract}

Keywords: vocal music education, chorus club, vocal health, choral training, vocal hygiene

\section{Introduction}

With more and more attention paid to whole person development, especially the new released policy of including art related content in high school entrance examination for Chinese students in junior high school, art education, especially vocal music-every individual's personal inherent instrument---has been a popular pursuit among adolescents and adults.

In college, chorus clubs serve as a channel to offer opportunities for students who are interested in learning choral singing, and as a window to exhibit college image. However, due to reasons such as, amateur participants who never receive professional vocal education, or teachers' inability to show choral members enough knowledge to protect their voice, many choral members suffer from temporal or permanent damage to their voice after terms of choral singing rehearsals.

Therefore, it is important to conduct research on the effectiveness of participating in chorus for college amateur students on improvement of singing and protection of vocal use. However, such area remains largely unexamined.

\section{Literature Review}

Current research focus on either occupational voice use problems or music majored students.

For example, investigations(Hendry, 2001; Sapair,1996) have found that teachers in general, may suffer various voice problems, from voice coarseness to dysphonia, due to voice misuse or overuse in and out of classroom instruction.

When Hendry (2001) examined 53 music teachers and other in terms of self-reported vocal health, he found a significant majority of vocal music teachers and almost half of instrumental music teachers had voice problems. What's more, non-music teachers reported more problems than music counterparts.

Sapair (1996) compared university students including pre-service music teachers and choral singers with non-singers, and found the former were more likely than the latter to report symptoms of potential voice problems, and the disorder might affect their professional career development.

As for the intervention to help improve students' vocal health, Scrimgeour and Meyer (2002) examined the effectiveness of an interactive educational program --"Ears for Listening, Voice for Speaking"-a hearing conservation and vocal hygiene program for 66 kindergarten students. Results indicated significant increase of students' knowledge regarding anatomy, abusive behaviors, and conservation practices.

Our search of the literature hardly found any studies that focused on issues of voice health among adolescent choristers participating weekly rehearsing as chorus club member for a long term.

In the period, instructors shall go through chorus singing instruction in general in addition to voice health issues in particular. Potential voice health matters before and after the experience among adolescent singers appears to have been less examined. 
The purpose of this study was to examine student perceived voice use and hygiene before and after joining a one-year chorus club.To that end, the following research question was designed.

Whether student's perceptions of their vocal condition and health are the same before and after 15 months' choral experience.

\section{Method}

\subsection{Participant}

The participants consist of 60 female chorus members, majoring in pre-school education, primary education or music education. They all passed initial test before admitted in the choir. $35 \%$ of the students reported to have participated in after-class vocal courses six months before applying to the choir. As for students' self-reported vocal singing levels (with the tests conducted by Shanghai Conservatory of Music for reference, which include junior, intermediate, and senior levels), 10\% think they have a accomplished junior level, $12 \%$ intermediate, and $8 \%$ senior.

\subsection{Survey}

Survey questions come from literature on vocal reports, such as Tepe, et al. (2002). Questions adopt a 7-point Likert-type scale, denoting a spectrum from agreement to disagreement. Choir members were surveyed prior to beginning of joining the choir in September 2015, and then surveyed at in December 2016. Survey were completed immediately after registration prior to choral training and Year End Campus Performance On stage 15 months later.

\subsection{Procedure}

15 months' chorus training covers an array of singing exercise (including warm-up exercises, breathing, resonance, dynamics, and diction), lecturing knowledge of vocal instrument (including posture breathing and sound) and recommending exemplary videos on chorus performance for students to appreciate after class.

Each week there was a 90-minute training session, each covering the instruction of vocal instrument, posture, breathing, sound, and voice health. Summer and winter holidays were spared out. In each session, time is approximately distributed according to the following schedule:

(1) warm up exercises (20 min),

(2) choral singing (55min),

(3) voice instruction of vocal instrument, posture, breathing, sound and voice health (15min)

As for the piece of choral work, we rehearsed five pieces, covering both Chinese works and Western ones. To be more specific, Chinese works were The dream of Dolma (four voice parts), You and Us (two parts), Pound Quarry (four parts) ; English works were Come To The Music (two parts) and Libertango (four parts). Each voice part is $\mathrm{S}_{I} \mathrm{~g}^{1}-\mathrm{g}^{2}, \mathrm{~S}_{\mathrm{II}} \mathrm{f}^{1}-\mathrm{f}^{2}, \mathrm{~A}_{\mathrm{I}}{ }^{\mathrm{b}} \mathrm{e}^{1}-\mathrm{e}^{2}$, and $\mathrm{A}_{I I}{ }^{\mathrm{b}} \mathrm{d}^{1}-{ }^{\mathrm{b}} \mathrm{d}^{2}$

For the pre survey, there were 60 girls responding, while for the post one, only 49 girls finished the survey. Paired T-test were used in SPSS 22

\section{Results}

Table 1 Pre and Post Comparisons of Self-reported Vocal Health

\begin{tabular}{|c|c|c|c|c|}
\hline \multirow{2}{*}{ Topic } & \multicolumn{2}{|c|}{ Mean Scores } & \multirow{2}{*}{$\mathrm{t}$} & \multirow[b]{2}{*}{$\mathrm{p}$} \\
\hline & Pre & Post & & \\
\hline $\begin{array}{l}\text { Today, I can comfortably sing the higher notes of my voice range } \\
\text { (Q1) }\end{array}$ & 4.92 & 5.55 & -4.55 & $.00 *$ \\
\hline $\begin{array}{l}\text { Today, I can comfortably sing the lower notes of my voice range } \\
\text { (Q2) }\end{array}$ & 4.71 & 5.53 & -4.33 & $.00 *$ \\
\hline Today, I can sing softly without any difficulty (Q3) & 4.63 & 5.59 & -6.01 & $.00 *$ \\
\hline Today, I can sing loudly without any difficulty (Q4) & 4.35 & 5.29 & -5.20 & $.00 *$ \\
\hline Today, my voice is hoarse (Q5) & 2.04 & 2.10 & -.28 & .78 \\
\hline
\end{tabular}


Table 1, cont.

Today, my voice feels tired (Q6)

$\begin{array}{llll}2.84 & 2.67 & .62 & .54\end{array}$

Today, my voice sounds creaky and dry (Q7)

3.80

2.63

$4.63 \quad .00^{*}$

Today, my throat hurts when I sing (Q8)

2.51

Today, I feel like I'm straining when I sing (Q9)

4.24

I have taken good care of my voice this past week (Q10)

4.27

2.33

$.76 \quad .45$

Today, I find myself clearing my throat a lot today (Q11)

2.80

$5.15 \quad .00^{*}$

4.06

4.94

$-3.25 \quad .00 *$

Today, my voice is breathy and much effort for me to sing/talk

2.90

$5.99 \quad .00^{*}$

$\begin{array}{llll}3.49 & 2.53 & 5.14 & .00^{*}\end{array}$

$\mathrm{N}=49$

Table 1 shows the result of paired T-test of responses to the 12 vocal healthy questions, before and after 15 months' choral training experiences.

Responses to three questions don't' differ significantly: hoarseness, $\mathrm{t}(48)=-.28, \mathrm{p}=.78$; tiredness, $\mathrm{t}(48)=.62, \mathrm{p}=.54$; and pain of throat, $\mathrm{t}(48)=.76, \mathrm{p}=.45$.

Other nine questions show significant improvement including use of voice in higher notes, $\mathrm{t}$ $(48)=-4.55, \mathrm{p}<.01$; lower notes, $\mathrm{t}(48)=-4.33, \mathrm{p}<.01$; singing softly, $\mathrm{t}(48)=-6.01, \mathrm{p}<.01$; singing loudly, $\mathrm{t}(48)=-5.20, \mathrm{p}<.01$; dryness, $\mathrm{t}(48)=4.63, \mathrm{p}<.01$; straining to sing, $\mathrm{t}(48)=-5.15, \mathrm{p}<.01$; assessment on how well each took care of the voice, $\mathrm{t}(48)=-3.25, \mathrm{p}<.01$; throat cleaning, $\mathrm{t}(48)=5.99, \mathrm{p}<.01$; effort to sing, $\mathrm{t}(48)=5.14, \mathrm{p}<.01$

\section{Discussion}

Though the sample size is not large enough and one school chorus is far from a representative reflecting other group choral setting, the results confirmed effective outcome of the chorus club experience.

Students reported improvement in controlling their voice and voice hygiene, especially in the aspects of dryness, staining, which means students, during the training period, has made improvement in controlling dynamics in projecting their voice, which is the foundation for sustained learning and singing.

As for the healthy use habits, students reported that they've done well, acquiring more knowledge and put it into practice, which in part accounts for their improvement in vocal use and competence. However, according to the table, no significant difference is found in terms of hoarseness, tiredness, and throat pain, which implies potential teaching content for the future.

According to Bowers \& Daugherty (2008), after intense use of voice in a chorus camp, high school student singers tend to show symptoms of hoarseness, vocal tiredness, dryness, throat pain, throat pain, effort to sing/breathiness, which need addressing in training sessions.

Similarly, Tepe, et al. (2002) surveyed singers $(\mathrm{N}=129)$ participating in youth choirs. Participants reported voice problems at the time of the survey, included, hoarseness, fatigue, change in voice range, tickling or choking sensation, volume disturbance, and breathiness. Over a third of these singers $(43 \%)$ felt they had to strain their voices when singing, while $31 \%$ reported a sensation of "over-singing" in choral rehearsals. And that's one of the major concern for this chorus training.

In our research, the outcome is comparatively more positive than previous studies. Possible reasons lie in the instructors' professional knowledge on vocal protection and hygiene, and emphasis on scientific design in terms of training intensity and timing intervention.

On the other hand, students self-reported lack of difference in hoarseness, fatigue, and pain of throat may also be explained by student purposefully failing to bring their full potential into full play, or the singing intensity is never designed strong or long enough to exhaust them. This problem shall be leaved for future research.

What's more, the lack of improvement in our study also implies further efforts in aspects of instruction, knowledge lecturing, and performance design, namely, the control of relevant muscles in specific organs, through explicit methods such as videos, model tools, and performances. 


\section{Conclusion}

In conclusion, this study proved significant positive impact of 15 months' chorus training on members' certain aspects of singing skills, including use of voice in higher and lower notes, singing softly and loudly; dryness, straining to sing, assessment on how well each took care of the voice, throat cleaning, and effort to sing; yet no significant improvement is shown in aspects of hoarseness, tiredness, and pain of throat, which leave space for further study.

\section{References}

[1] Sapir, Shimon, Barbara Mathers - Schmidt, and George W. Larson: Singers' and non - singers' vocal health, vocal behaviours, and attitudes towards voice and singing: indirect findings from a questionnaire. International Journal of Language \& Communication Disorders Vol.31.2 (1996), p.193-209

[2] E. S. Tepe, E. S. Deutsch, Q. Sampson, et al.: A pilot survey of vocal health in young singers. Journal of Voice Vol.16.2 (2002), p. 244-250

[3] J. Bowers, and J. F. Daugherty: Self-reported student vocal use at a high school summer choral camp. International Journal of Research in Choral Singing Vol. 3.1 (2008), p. 25-37

[4] K. L. Hendry: Burnout and self-reported vocal health among music teachers and other educators. Dissertation Abstracts International Vol. 62.05 (2001)

[5] K. Scrimgeour, and S. E. Meyer: Effectiveness of a hearing conservation and vocal hygiene program for kindergarten children. Special Services in the Schools Vol.18.1-2 (2002), p. 133-150

[6] S. Tonkinson: The Lombard effect in choral singing. Journal of Voice Vol.8.1 (1994), p. 24-29

[7] M, Olson: The solo singer in the choral setting: A handbook for achieving vocal health. Scarecrow Press (2010).

[8] B. Smith, and T. S. Robert: Choral pedagogy. Plural Publishing(2013) 